
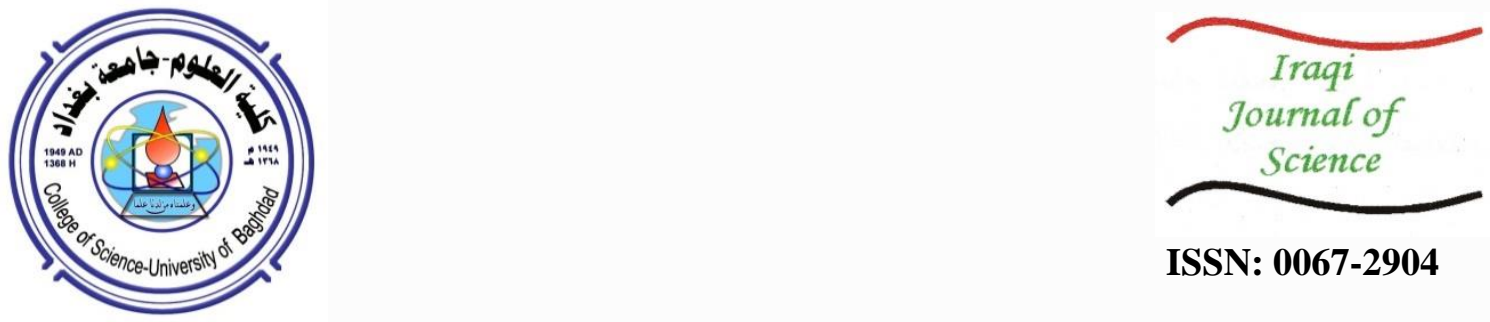

ISSN: 0067-2904

\title{
Preliminary Assessment of the Soil Foundation Characteristics Utilizing the 2D Resistivity Imaging and Down-Hole Seismic Refraction Techniques: A Case Study in Tenth of Ramadan City, Egypt
}

\author{
Shokry A. Soliman*, Salah Shebl, Ahmed El Khafif, T.F. Shazley, M.H. Farag \\ Laboratory of geophysics, Egyptian Petroleum Research Institute, Cairo, Egypt
}

Received: 30/10/2020

Accepted: 9/1/2021

\begin{abstract}
Two-dimensional electrical resistivity imaging and seismic refraction, in the form of down-hole survey, were applied to delineate the subsurface section and elastic moduli and identify geotechnical characteristics of subsurface materials in the $10^{\text {th }}$ of Ramadan industrial area, Cairo, Egypt. The results of four 2-D profiles of electrical resistivity, in the form of dipole-dipole and Wenner configurations, revealed that the subsurface section contains two main geo-electrical layers; the first is made of sand, some silt, and gravels, reflecting low resistivity values ranging from 25 to $65.5 \mathrm{ohm} \mathrm{m}$. This layer is overlying a high resistivity layer (65.5 to135 ohm m), corresponding to medium to coarse sand, with gravel and calcareous materials. It is worth noting that that the down-hole technique was used to measure velocities of $\mathrm{P}$ and $\mathrm{S}$ waves in order to derive the low strain dynamic elastic properties, such as Poisson's ratio, Shear modulus, stress ratio, concentration index, $\mathrm{N}$-value, and the ultimate and allowable bearing capacities of the subsurface soil, down to an approximate depth of $30 \mathrm{~m}$ in the borehole at the site. In addition, the Vs30 value was calculated and revealed that the soil is categorized as a NEHRP class (D). Furthermore, the results of geotechnical parameters and elastic moduli were found to be realistic and sensible for the purposes of engineering constructions and imply that the soil in the study area is characterized by fairly to moderately competent quality. A new empirical correlation is proposed between the obtained Vs and resistivity values, where Vs = $1.0302 \rho+172.74$.
\end{abstract}

Keywords: 2D resistivity imaging, seismic refraction, geotechnical parameters, down-hole, $\mathrm{Vs}^{30}$

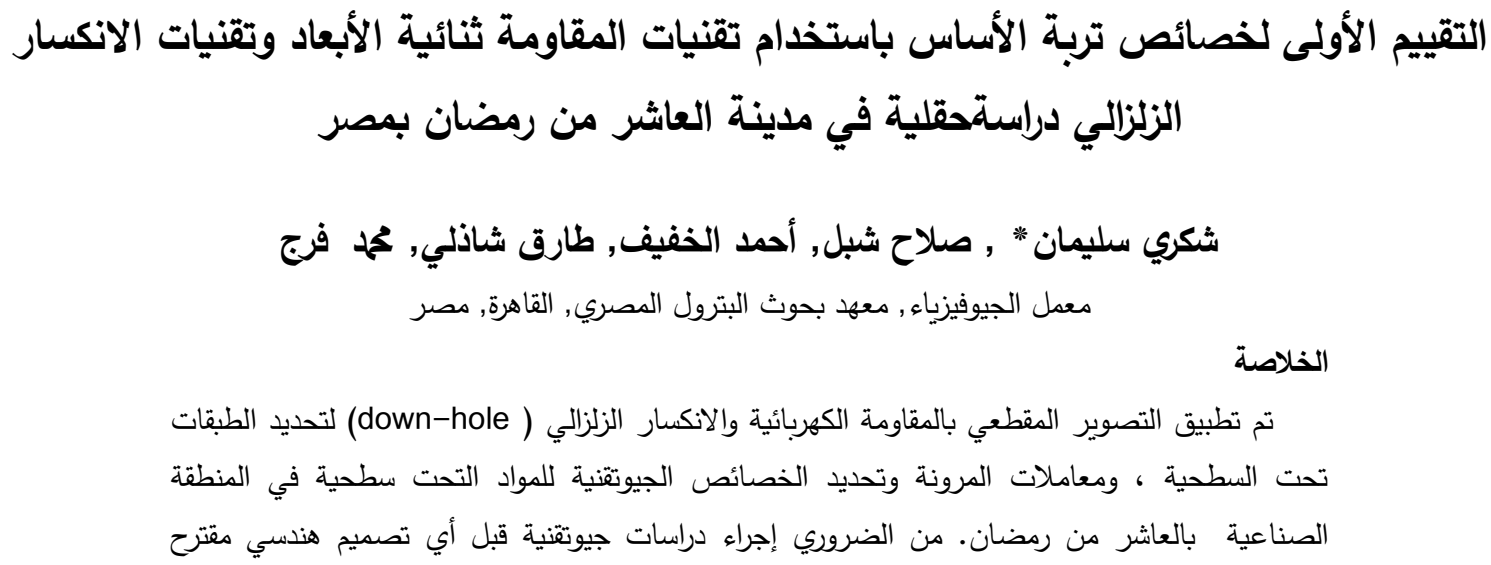




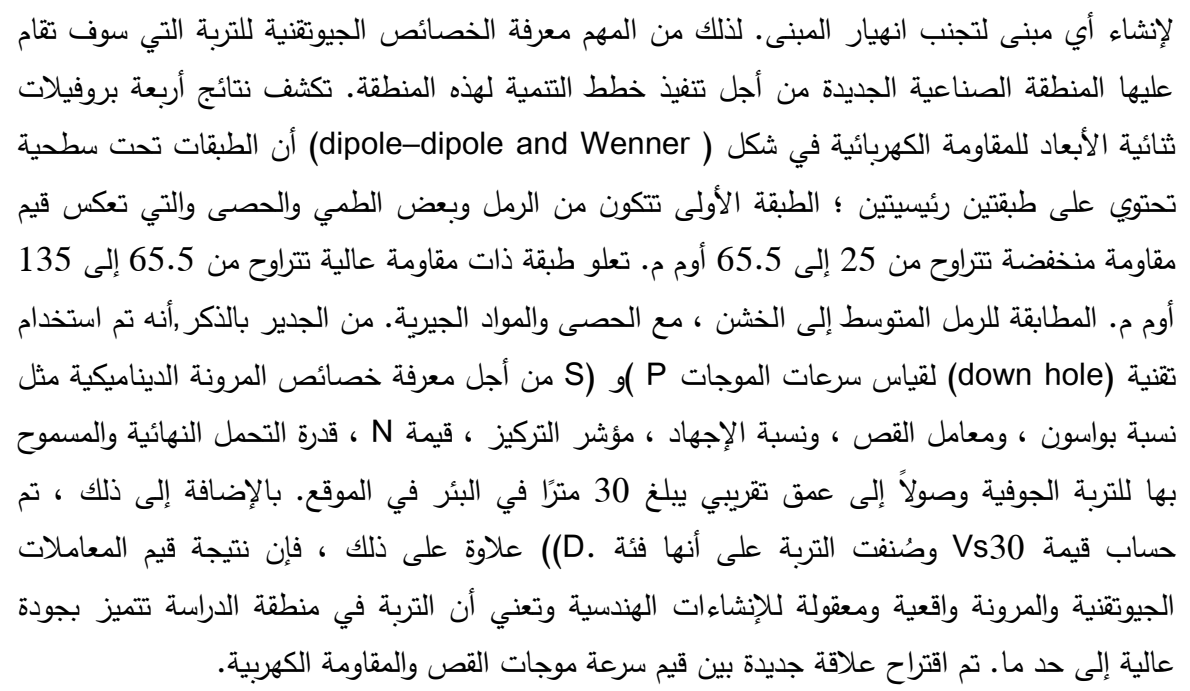

\section{Introduction}

A geotechnical study is necessary before any proposed engineering design to construct any building to prevent the building from collapsing. It is important to know the geotechnical properties of the soil on which a new industrial zone, for example, is to be built in order to implement the development plans of this zone. Nowadays, the combination of geoelectrical resistivity and seismic refraction techniques for site investigations is very effective due to their distinct geophysical response with varying resolution. In some geotechnical problems, geophysical studies may be adopted to decide which execution measure should be taken to diminish costs, effort, time, and even the chance of accidents during any constructions.

Several studies used effective geophysical techniques in engineering problems, such as the detection of the ancient foundations, cracks and fractures of building [1,2], planning on new cities, building new neighborhood, [3-5] and the investigations of shallow subsurface sections, environmental problems and geotechnical parameter [6, 7].

The City of Tenth of Ramadan has been witnessing civil and industrial development represented in constructing new industrial zones, since its establishment in 1977. It is located along the Cairo-Ismailia desert highway about $55 \mathrm{~km}$ from Cairo. It lies between latitudes $30^{\circ} 17^{\prime}$ and $30^{\circ} 25^{\prime} \mathrm{N}$ and longitudes $31^{\circ} 34^{\prime}$ and $31^{\circ} 49^{\prime} \mathrm{E}$. The area of study is located within the northeast territory of $10^{\text {th }}$ Ramadan City (Figure 1). The shallow seismic refraction and Dc resistivity were utilized in defining the geotechnical properties of the soil and rocks $[8,9]$, where shear waves velocity has an intimate relationship with the rigidity or stiffness of the soil or rocks [10], which can be expressed as the elastic shear modulus.

The present study aims to investigate the lateral and vertical variations in the subsurface sections, determine elastic moduli, and identify the geotechnical characteristics of the subsurface soil using integrated 2D electrical resistivity, borehole data, and down-hole (P and S) waves.

\section{Geology of the Study Area}

The investigated site and its vicinity are covered by sedimentary rocks (Figure 2) belonging to the Tertiary and Quaternary ages [11]. The subsurface sequences of the uppermost thirty meters of the soil consist of very dense sand, coarse to medium sand, and silty sand (Figure 3), based on the information derived from the two boreholes drilled at the investigated site. 


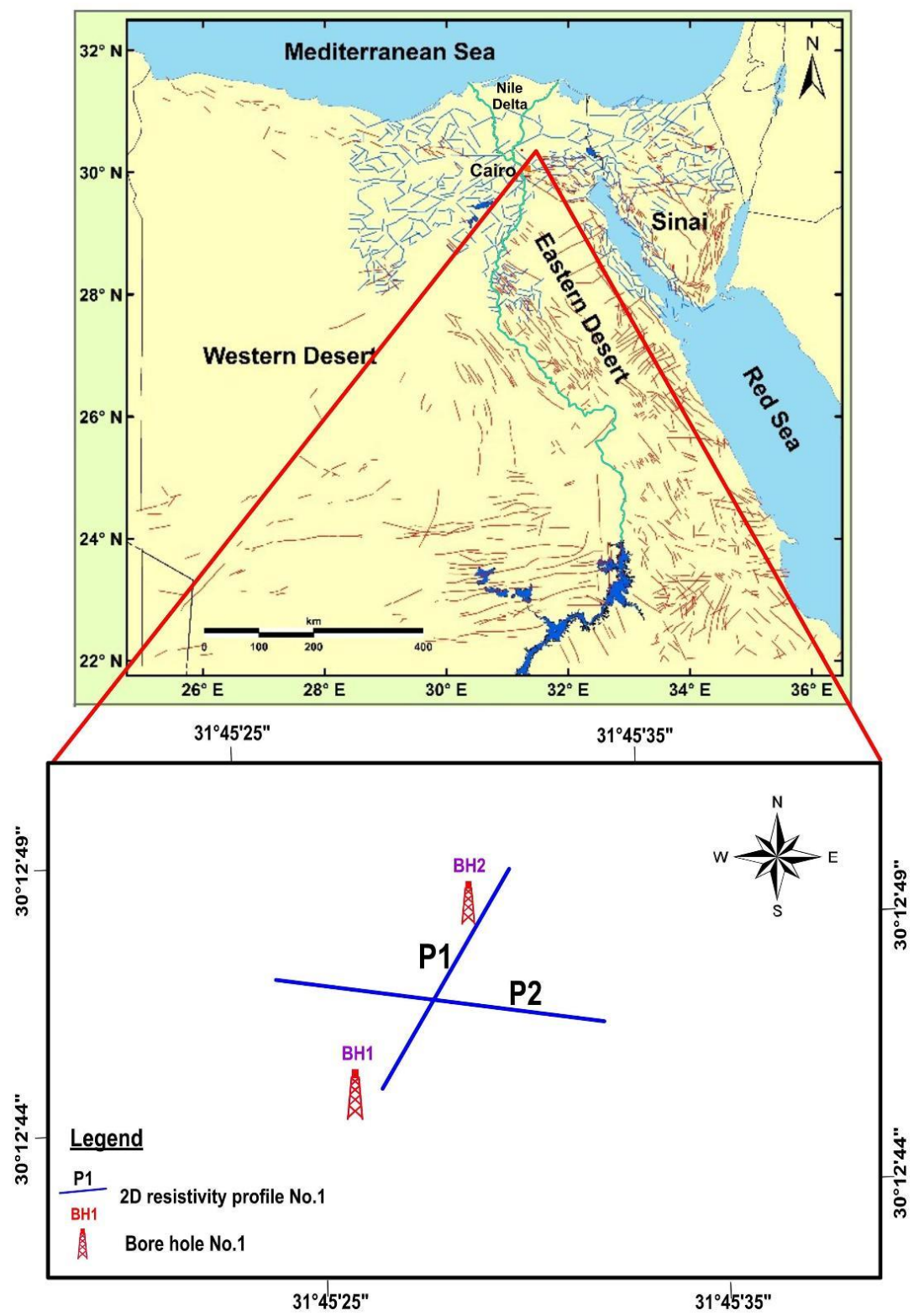

Figure 1- Location map of the study area, electrical resistivity stations, and boreholes sites

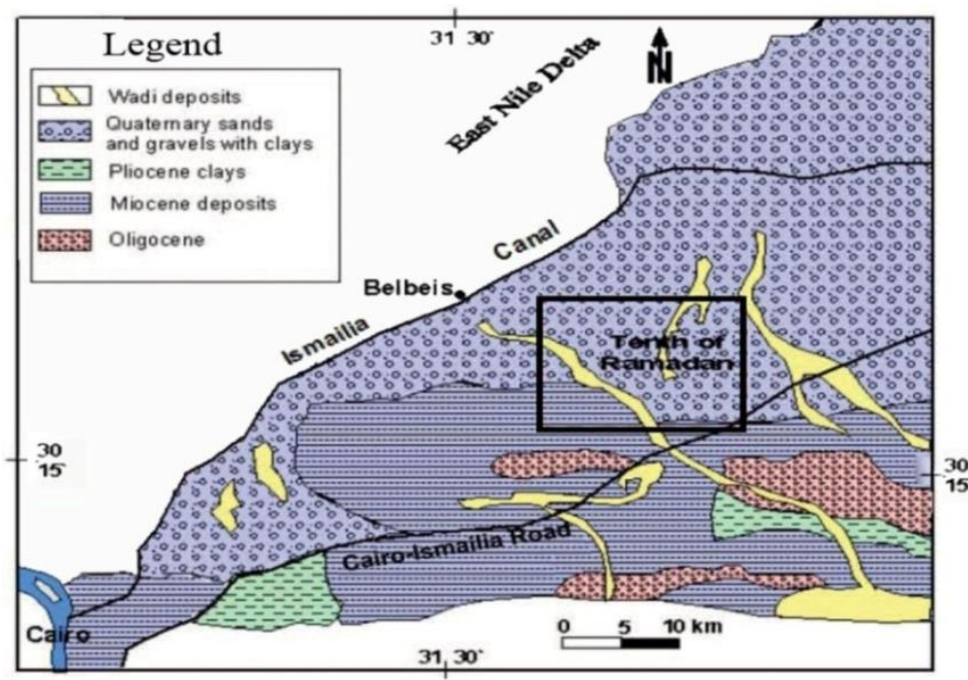

Figure 2- Modified surface geological map of the area and its surroundings [12]. 
BH 1

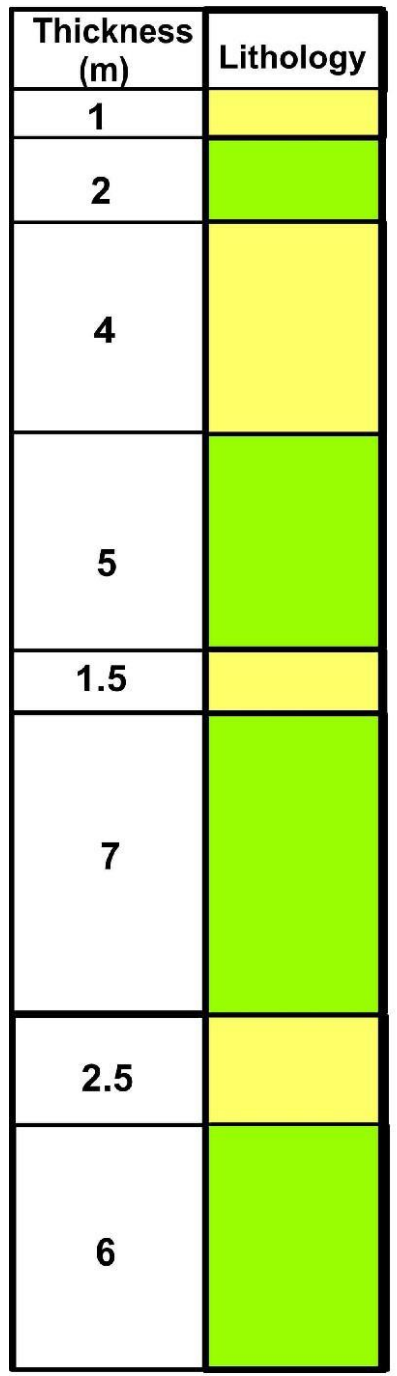

BH 2

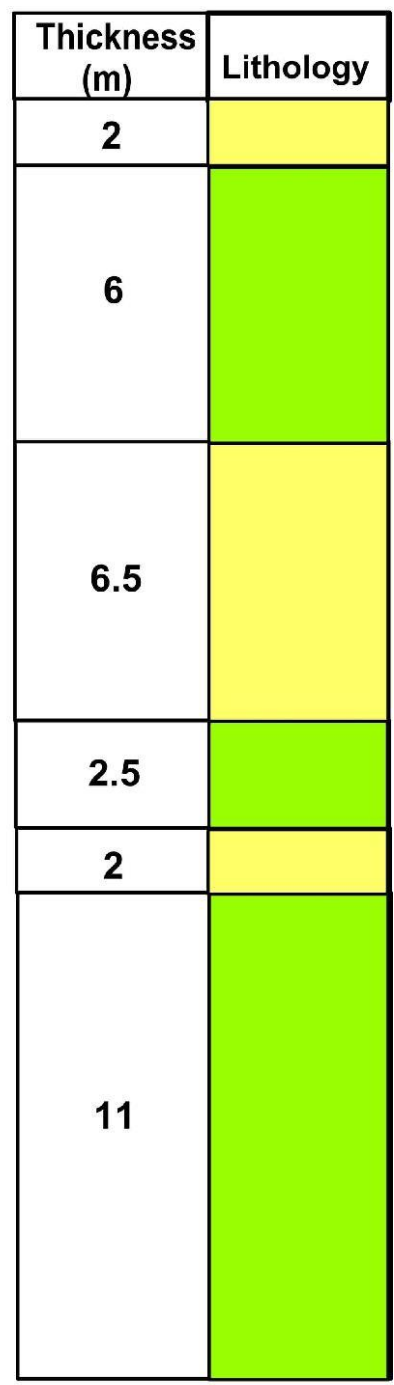

Very Dense, Sand, Medium to Coarse with Gravels and Calcareous materials.

Sand, Medium to Coarse, Some of silt and Calcareous materials.

Figure 3- Lithological description of the boreholes $\mathrm{BH} 1$ and $\mathrm{BH} 2$, [13]

\section{Methodology}

\section{D Resistivity Imaging}

The electrical resistivity imaging method was chosen in this study due to its ability to image the subsurface structure and thickness of layers. This technique has wide applications in environmental, engineering, and variable subsurface explorations [14, 15]. Four 2D resistivity profiles were carried out using dipole-dipole and Wenner arrays. The instrument used in the study is SYSCAL-Pro, 48 channels, with an automatic multi-electrode system made by IRIS Instruments, France. The first 2D profile (P1) is located between the two boreholes, while the second profile (P2) is orthogonal on P1 in the study area. Both profiles were measured using dipole-dipole array (Figure 1). In additions, another two profiles of Wenner array were executed at the same locations of dipole-dipole profiles, in order to compare the results of the two techniques. The data were processed and analyzed using RES2DINV program [16], which produces an image of the electrical resistivity distribution in the subsurface based on a regularization algorithm [17]. 
The inversion routine used by RES2DINV is based on the smoothness constrained leastsquares technique [18] which offers three options, providing a very fast quasi Newton method [17]. The program automatically creates a 2D invers model by dividing the subsurface into rectangular blocks and chooses optimum inversion parameters for the data, which include the damping factor, vertical to horizontal flatness filter ratio, convergence limit, and number of iterations. The program calculates the apparent resistivity values of the model blocks using either a finite difference or finite element method and compares these to measured data. The resistivity of the model blocks is adjusted iteratively until the calculated apparent resistivity values of the model agree with the actual field measurements.

\section{Seismic Refraction Tools}

Seismic refraction was executed by applying a down-hole technique to measures the compression wave (P) and the shear wave (S) in the borehole using a seismograph model McSEIS-SXW manufactured by OYO Company. During down-hole seismic testing, a seismic source is generated at distance of about $1 \mathrm{~m}$ from a well. A sledge hammer $(10 \mathrm{~kg})$ was used to generate both compression (P) and shear (S) waves by striking the loaded plate. Relying on the type of strike plate on the ground surface (vertical or horizontal), the seismic source can generate a signal containing a maximum of energy in the compression wave (P) or the shear wave $(\mathrm{S})$, respectively. Within the borehole, a receiver geophone measured the arrival times by varying its location every $1 \mathrm{~m}$ until the $30 \mathrm{~m}$ depth to determine the $\mathrm{P}$ and $\mathrm{S}$ wave velocities (Figure 1). The data were recorded and saved as separate files for each shot for both $\mathrm{P}$ and $\mathrm{S}$ waves corresponding to each depth location.

The down-hole technique is a vital method of the seismic refraction surveys for determining the shear wave velocity and, consequently, estimating the elastic situation (stiffness) of the soil or rock for geotechnical and engineering purposes.

\section{Elastic Moduli and Geotechnical Parameters}

The values of $\mathrm{P}$ - and S-wave velocities which concluded from the two boreholes measurements were used to evaluate the different elastic moduli, such as density (Eq.1), Poisson's ratio (Eq. 2) [19-21], shear modulus (Eq. 3) [22], Young's modulus (Eq. (4) [23, 24], and bulk modulus (Eq. 5) [25], as listed in (Table 4).

$$
\begin{aligned}
& \text { Density }(\rho)=\quad 0.3 \mathrm{Vp} .25 \\
& \text { Poisson's ratio }=\frac{V_{P}{ }^{2}-2 V_{s}{ }^{2}}{2\left(V_{P}{ }^{2}-V_{S}{ }^{2}\right)} \\
& \text { Shear modulus }(\mu)=\rho \mathrm{VS}^{L^{2}} \\
& \text { Young's modulus }(\mathrm{E})=2 \mu(1+\sigma) . \\
& \text { Bulk's modulus }(\mathrm{K}=\mathrm{E} / 3(1-2 \delta)
\end{aligned}
$$

\section{The Geotechnical Elements}

The geotechnical elements, such as the $\mathrm{N}$-value, concentration index, material index, stress ratio, and bearing capacity were evaluated as follows.

\section{N-Value}

The $\mathrm{N}$-value is one of the most common geotechnical parameters, known as SPT (Standard Penetration Test). It can be calculated in situ from a well to investigate the status of cohesion-less deposits, where the low competent rocks reveal low $\mathrm{N}$-value and vice versa. The measurements of SPT N values depend on many factors, such as drilling methods, drill rods, borehole properties (e.g. diameter and stabilization, the sampler, blow count rate, hammer configuration, fine content), energy corrections, and test procedure [26,27]. Geophysically, the N-value is determined from the modified equation by [28] 


$$
\mathrm{Vs}=89.9(\mathrm{~N}) 0.341
$$

To calculate the $\mathrm{N}$ value, this equation can be rewritten as:

$$
\log \mathrm{N}=2.932 \log \mathrm{VS}-5.7295
$$

Shear wave data can be converted to SPT N-values, to recognize the type of soil or sediment, and used in calculating bearing capacity. The $\mathrm{N}$-value was originally adopted to investigate the status of cohesionless deposits, but it is widely used in both cohesionless and cohesive deposits for exploration in all types of foundations (Table 1).

Table 1- N-value classes (modified after [29].

\begin{tabular}{cllll}
\hline \multicolumn{2}{c}{ Cohesive soil } & \multicolumn{2}{c}{ Cohesionless soil } \\
\hline N-value & \multicolumn{2}{c}{ Description } & N-value & Description on \\
\hline$<4$ & Very soft & $0-10$ & Loose \\
$4-6$ & Soft & 11 & Medium \\
$7-15$ & Medium & $31-50$ & Dense \\
$16-25$ & Stiff & $>50$ & Very dense \\
$>25$ & Hard & &
\end{tabular}

Table 2- Comparison between SPT N value, shear wave velocity Vs, and Poisson's ratio according to [30-31].

\begin{tabular}{cccc}
\hline Soil type & SPT N value & S-wavevelocity $\mathbf{~ m / s}$ & Poisson's ratio \\
\hline $\begin{array}{c}\text { Loose } \\
\text { granular soil }\end{array}$ & $0-20$ & $130-280$ & $0.2-0.4$ \\
$\begin{array}{c}\text { Dense } \\
\text { granular soil }\end{array}$ & $20-50$ & $200-410$ & $0.3-0.45$ \\
Soft clay & $0-6$ & $40-90$ & $0.15-0.25$ \\
Stiff clay & $6-30$ & $65-140$ & $0.2-0.5$ \\
\hline
\end{tabular}

\section{Concentration Index}

The concentration index is one of the engineering parameters that reveal the degree of the competence of materials used in the foundation and other civil constructions. It depends on two factors; one is the elastic moduli of the substance and the other is depth-pressure distribution [29].

\section{Material Index}

$$
C_{i}=\frac{(3-4 \alpha)}{(1-2 \alpha)}
$$

From the engineering perspective, the material index clarifies the material quality for foundation purposes. This parameter implies the degree of competence based on the elastic moduli. This index depends on several factors, such as matter composition, grade of consolidation, fracturing, jointing, and presence or absence of fluids in pore spaces, which affect the medium of the materials and the wave velocities [29].

$$
\xi=(1-4 \sigma) \text {. }
$$

Table 3- Soil description according to Poisson's Ratio and Material Index, after [32].

\begin{tabular}{ccccc}
\hline $\begin{array}{c}\text { Soil } \\
\text { description }\end{array}$ & $\begin{array}{c}\text { Incompetent to } \\
\text { slightly } \\
\text { competent }\end{array}$ & $\begin{array}{c}\text { Fairly to } \\
\text { Moderately } \\
\text { competent }\end{array}$ & $\begin{array}{c}\text { Competent } \\
\text { Material }\end{array}$ & $\begin{array}{c}\text { Very high } \\
\text { Competent }\end{array}$ \\
\hline Poisson's Ratio & $0.41-0.49$ & $0.35-0.27$ & $0.25-0.16$ & $0.12-0.03$ \\
Material Index & $(-0.5)-(-1)$ & $-0.5-0.0$ & $0.0-0.5$ & $>0.5$ \\
\hline
\end{tabular}




\section{Bearing Capacity}

In geotechnical engineering, the bearing capacity is a gauge for structural stability of the soil. The failure criterion for any foundation soil is known by the ultimate bearing capacity and it is considered an important factor in soil mechanics [23].

\section{Allowable bearing capacity (Qa)}

It is defined as the maximum load to be considered to avoid shear failure. It can be reduced from the ultimate bearing capacity value by the value of safety factor $(\mathrm{F})$, according to [33].

$$
\text { Qa } \quad 1 / 4 \quad \text { Qult=F }
$$

where Qa is the allowable bearing capacity and Fs is the factor of safety $(\mathrm{F})$, which equals three for cohesive soils. This equation can be rewritten in terms of shear velocity in the case of cohesive soils, as follows:

$$
\begin{array}{lllllll}
\log & \mathrm{Qa} & = & 2.932 & \log & \mathrm{V} & -
\end{array}
$$

For cohesionless soil,

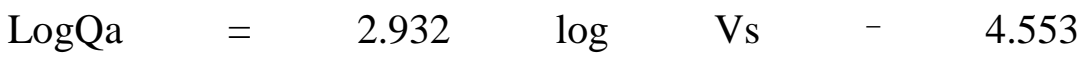

Where Vs is the shear-wave velocity, Qa is the allowable bearing capacity.

\section{Vs30 and site classification}

Shear-wave velocity has been utilized as an essential parameter for estimating the dynamic properties of soils since long time. VS30 is known as the average of shear-wave velocity in the top 30 meters, based on travel time from the surface to a depth of $30 \mathrm{~m}$. It is used to classify the soil into six classes ( A-F) according to the National Earthquake Hazards Reduction Program [34]. Vs30 can be calculated from Eq. (13).

$$
V_{\mathrm{s}}{ }^{30}=\frac{30}{\sum_{i=1}^{N}\left(h_{i} / v_{i}\right)},
$$

where $V I$ is shear-wave velocity in $\mathrm{m} / \mathrm{s}$, and $h i$ is the thickness of any layer (between 0 and $30 \mathrm{~m})$.

\section{Results and Discussion}

The integration between electrical, shear wave, and borehole data were used to estimate the dynamic characteristics of the subsurface soil, which could have direct effects on the constructions in the City of Tenth Ramadan. The geoelectrical data included 2-D resistivity data, where Wenner array indicated the vertical variation, while the dipole array reflected the horizontal and vertical variations. The results of inversion show that the dipole sections indicate horizontal variation, as shown in (Figure 4). The subsurface succession consists of two geologic units. The first layer consists of sand, silt, and gravel with low resistivity ranging from 25 to $65.5 \mathrm{ohm} \mathrm{m}$. The thickness of this layer increases toward the south, reaching about $12 \mathrm{~m}$ at nearest borehole 1 . The second layer has moderate resistivity, corresponding to dry sand with gravels and calcareous materials. The thickness of this layer is observed to increase in the center of the section and decreases toward the north nearest borehole 2. It can be distinguished at the depth range from $9 \mathrm{~m}$ at the north to $12 \mathrm{~m}$ toward the south.

The data of primary and shear waves obtained from boreholes were used to calculate the different elastic moduli, as listed in (Table 4). The values of Young's modulus (E) ranged 
between 0.029 and $0.537 \mathrm{GPa}$, Bulk modulus $(\mathrm{K})$ range between 0.030 and $0.991 \mathrm{GPa}$., and shear modulus $(\mu)$ or rigidity range between 0.011 and $2.00 \mathrm{Gpa}$. Poisson's ratio $(\sigma)$ was
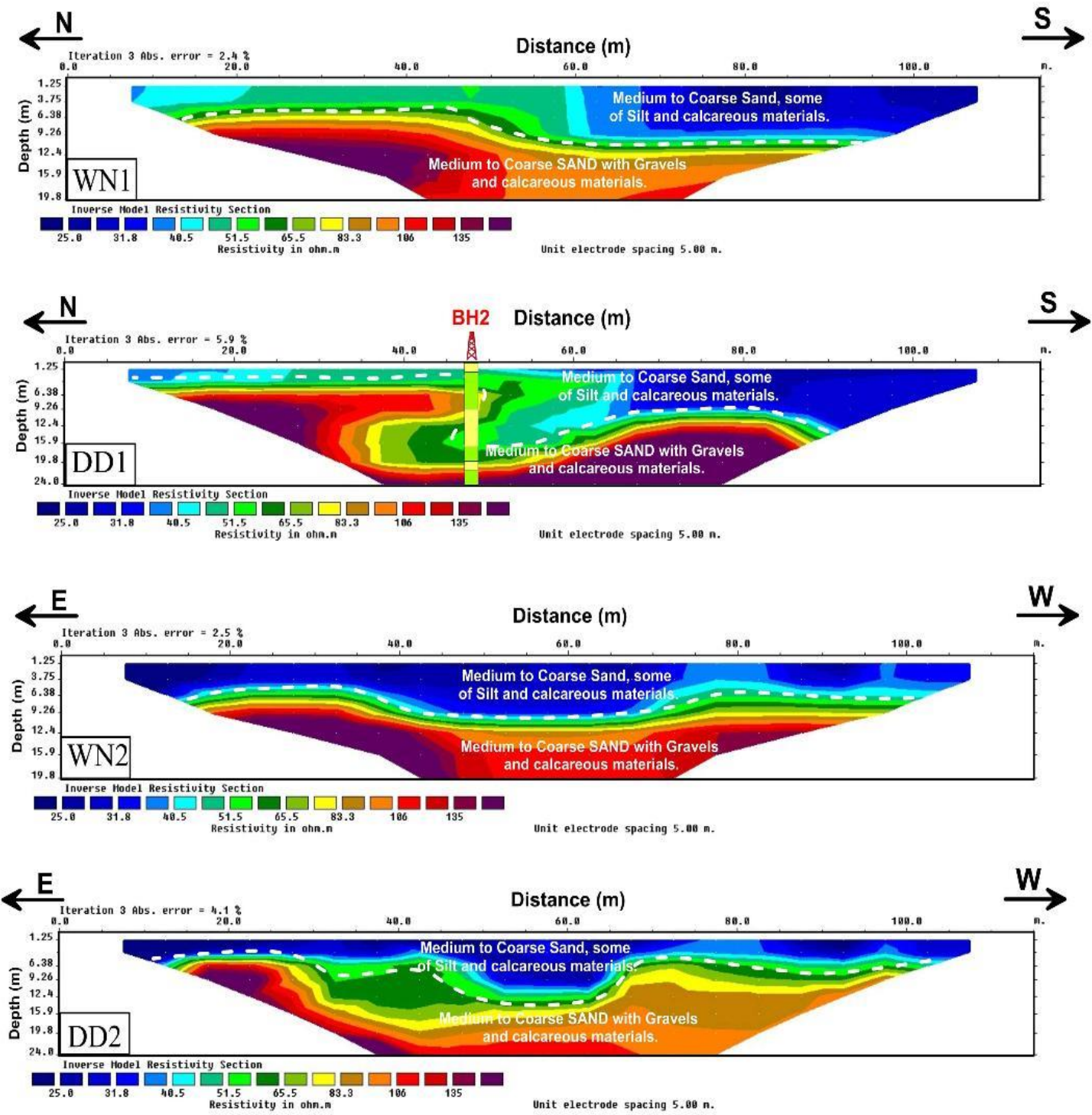

characterized by relative low ratio, ranging between 0.328 and 0.415 , revealing that the soils belong to dense granular soil, according to Table 2. SPT value is one of the most important parameters used to determine the mechanical properties of subsurface soil. The N-values ranged from 15.30 to 31.29 , which reflects medium to dense cohesionless soil, according to (Table 1).

Figure 4- The 2-D electrical resistivity inverted sections along the profiles of P1, represented by DD1 dipole-dipole

array and WN1 Wenner array and P2, represent by DD2 and WN2. 
Table 4- The elastic moduli values based on shear waves measured in boreholes 1 and 2.

\begin{tabular}{|c|c|c|c|c|c|c|c|c|c|c|c|c|}
\hline \multicolumn{6}{|c|}{ Borehole 1} & \multicolumn{7}{|c|}{ Borehole 2} \\
\hline $\begin{array}{l}\text { Dep. } \\
\text { E }\end{array}$ & $\underset{K}{V p} \quad V_{s}$ & $\delta$ & $\rho$ & $\mu$ & $\mathbf{E}$ & & $K$ & $V p$ & Vs & $\delta$ & $\rho$ & $\mu$ \\
\hline 1 & 19597 & 0.336 & 1.16 & 11 & 29 & 30 & & 264 & 130 & 0.340 & 1.25 & 21.1 \\
\hline 56.6 & 58.9 & & & & & & & & & & & \\
\hline 2 & 352173 & 0.341 & 1.34 & 40 & 108 & 11 & & 357 & 176 & 0.339 & 1.35 & 41.7 \\
\hline 111.8 & 116.1 & & & & & & & & & & & \\
\hline 3 & $438 \quad 208$ & 0.354 & 1.42 & 61 & 166 & 19 & & 390 & 190 & 0.344 & 1.38 & 49.7 \\
\hline 133.7 & 143.2 & & & & & & & & & & & \\
\hline 4 & $495 \quad 245$ & 0.338 & 1.46 & 88 & 235 & 24 & & 457 & 226 & 0.338 & 1.43 & 73.2 \\
\hline 195.9 & 201.7 & & & & & & & & & & & \\
\hline 5 & 559283 & 0.328 & 1.51 & 121 & 321 & 31 & & 474 & 229 & 0.348 & 1.45 & 75.9 \\
\hline 204.5 & 223.8 & & & & & & & & & & & \\
\hline 6 & $583 \quad 287$ & 0.340 & 1.52 & 125 & 336 & 351 & & 532 & 261 & 0.342 & 1.49 & 101.4 \\
\hline 272.1 & 286.1 & & & & & & & & & & & \\
\hline 7 & 614303 & 0.339 & 1.54 & 142 & 379 & 393 & & 551 & 269 & 0.344 & 1.50 & 108.7 \\
\hline 292 & 311.1 & & & & & & & & & & & \\
\hline 8 & $642 \quad 314$ & 0.343 & 1.56 & 154 & 413 & 438 & & 567 & 281 & 0.337 & 1.51 & 119.4 \\
\hline 319.4 & 327.1 & & & & & & & & & & & \\
\hline 9 & 856326 & 0.415 & 1.68 & 178 & 504 & 991 & & 563 & 277 & 0.340 & 1.51 & 115.9 \\
\hline 310.6 & 324.2 & & & & & & & & & & & \\
\hline 10 & 851324 & 0.415 & 1.67 & 176 & 498 & 978 & & 576 & 279 & 0.347 & 1.52 & 118.2 \\
\hline 318.4 & 346.2 & & & & & & & & & & & \\
\hline 11 & 647316 & 0.343 & 1.56 & 157 & 420 & 446 & & 596 & 290 & 0.345 & 1.53 & 128.8 \\
\hline 346.5 & 372.3 & & & & & & & & & & & \\
\hline 12 & 638302 & 0.356 & 1.56 & 142 & 385 & 445 & 590 & 284 & & 349 & .53 & 123.2 \\
\hline 332.5 & 367.5 & & & & & & & & & & & \\
\hline 13 & 655311 & 0.354 & 1.57 & 152 & 411 & 471 & 592 & 288 & & 345 & .53 & 126.8 \\
\hline 341.2 & 366.8 & & & & & & & & & & & \\
\hline 14 & 658320 & 0.345 & 1.57 & 161 & 433 & 465 & 588 & 289 & 0.341 & 1.53 & & 127.5 \\
\hline 341.9 & 357.8 & & & & & & & & & & & \\
\hline 15 & 667329 & 0.339 & 1.58 & & 171 & 457 & 474 & 616 & $5 \quad 300$ & 0.345 & 51.54 & \\
\hline 139.0 & $373.8 \quad 4$ & 0.7 & & & & & & & & & & \\
\hline 16 & 686337 & 0.341 & 1.59 & & 180 & 483 & 506 & 604 & +308 & 0.324 & 1.54 & \\
\hline 145.8 & 386.13 & 56.3 & & & & & & & & & & \\
\hline 17 & 682333 & 0.343 & 1.58 & & 176 & 472 & 503 & 641 & 322 & 0.331 & 1.56 & \\
\hline 161.7 & $430.6 \quad 4$ & 25.3 & & & & & & & & & & \\
\hline 18 & 688340 & 0.338 & 1.59 & & 184 & 491 & 507 & 640 & 322 & 0.331 & 1.56 & \\
\hline 161.7 & $430.2 \quad 4$ & 3.1 & & & & & & & & & & \\
\hline 19 & 689340 & 0.339 & 1.59 & & 184 & 492 & 509 & 634 & 312 & 0.340 & 1.56 & \\
\hline 151.4 & $405.9 \quad 4$ & 3.4 & & & & & & & & & & \\
\hline 20 & 695335 & 0.349 & 1.59 & & 179 & 482 & 531 & 639 & 316 & 0.338 & 1.56 & \\
\hline 155.6 & $416.5 \quad 4$ & 28.9 & & & & & & & & & & \\
\hline 21 & 696339 & 0.344 & 1.60 & & 183 & 492 & 527 & 614 & 308 & 0.332 & 1.54 & \\
\hline 146.4 & $389.9 \quad 3$ & 36.6 & & & & & & & & & & \\
\hline 22 & 701343 & 0.343 & 1.60 & & 188 & 504 & 534 & 653 & 320 & 0.342 & 1.57 & \\
\hline 160.5 & $430.7 \quad 4$ & 5.3 & & & & & & & & & & \\
\hline 23 & 701343 & 0.343 & 1.60 & & 188 & 504 & 534 & 647 & 321 & 0.337 & 1.56 & \\
\hline 161.1 & $430.7 \quad 4$ & 39.7 & & & & & & & & & & \\
\hline
\end{tabular}




\begin{tabular}{|c|c|c|c|c|c|c|c|c|c|c|}
\hline 24 & 718350 & 0.344 & 1.60 & 197 & 528 & 565 & 633 & 314 & 0.337 & 1.55 \\
\hline 153.3 & 409.9 & 8.6 & & & & & & & & \\
\hline 25 & 718347 & 0.348 & 1.60 & 193 & 521 & 570 & 646 & 318 & 0.340 & 1.56 \\
\hline 158.0 & 423.6 & 1.5 & & & & & & & & \\
\hline 26 & 713351 & 0.340 & 1.60 & 197 & 529 & 551 & 653 & 324 & 0.337 & 1.57 \\
\hline 164.5 & $439.8 \quad 4$ & 8.9 & & & & & & & & \\
\hline 27 & 713353 & 0.338 & 1.60 & 200 & 534 & 548 & 644 & 318 & 0.339 & 1.56 \\
\hline 157.9 & 422.8 & 7.1 & & & & & & & & \\
\hline 28 & 717349 & 0.345 & 1.60 & 195 & 525 & 564 & 664 & 321 & 0.348 & 1.57 \\
\hline 162.1 & 437.0 & 7.6 & & & & & & & & \\
\hline 29 & 720353 & 0.342 & 1.61 & 200 & 537 & 566 & 675 & 327 & 0.347 & 1.58 \\
\hline 169.0 & 455.14 & 4.7 & & & & & & & & \\
\hline 30 & 720349 & 0.346 & 1.61 & 196 & 527 & 572 & 698 & 333 & 0.353 & 1.59 \\
\hline
\end{tabular}

Dep. = depth $(\mathrm{m}), \mathrm{Vp}=\mathrm{P}$-wave velocity $(\mathrm{m} / \mathrm{sec}), \mathrm{Vs}=\mathrm{S}$-wave velocity $(\mathrm{m} / \mathrm{sec}), \sigma=$ Poisson's ratio, $\boldsymbol{\rho}=$ density $\mathrm{gm} / \mathrm{cm} 3, \mathrm{~m}=$ shear modulus $(\mathrm{GPa}), \mathrm{E}=$ Young's modulus (GPa), $\mathrm{K}=$ bulk modulus (GPa).

The engineering parameters were calculated and the results are summarized in table 5, whereas the complete results are plotted in Figures 5 and 6. Interestingly, when these results were extrapolated, several noteworthy results were found.

The Concentration Index (Ci) value of the soil ranged between 3.41 at the depth of $9 \mathrm{~m}$, 4.08 in $\mathrm{BH} 1$, and 3.86 to 4.08 in BH2 (Figure 5).

Stress Ratio ( $\mathrm{Si}$ ) values ranged between 0.505 and 0.710 in $\mathrm{BH} 1$ and 0.480 to 0.545 in $\mathrm{BH} 2$. The Material Index (Mi) values ranged from -0.41 to -0.31 in $\mathrm{BH} 1$ and $\mathrm{BH} 2$.

Ultimate Bearing Capacity (Qult) values ranged between 459 and 939 in BH1and 568 to 917 in $\mathrm{BH} 2$, while the uppermost layers, within $6 \mathrm{~m}$, had the lowest values of allowable Bearing Capacity (Qa) and the rest of the layers had the highest values (Figure 6).

$\mathrm{N}$ values ranged from 15 to 31.2 in $\mathrm{BH} 1$ and 19 to 30.5 in $\mathrm{BH} 2$. Most of the upper layers, above $6 \mathrm{~m}$, were characterized by the lowest $\mathrm{N}$ values, while these values increased with increasing depth in boreholes (Figures 5 and 6).

Table 5-The calculated geotechnical engineering parameters from two boreholes data.

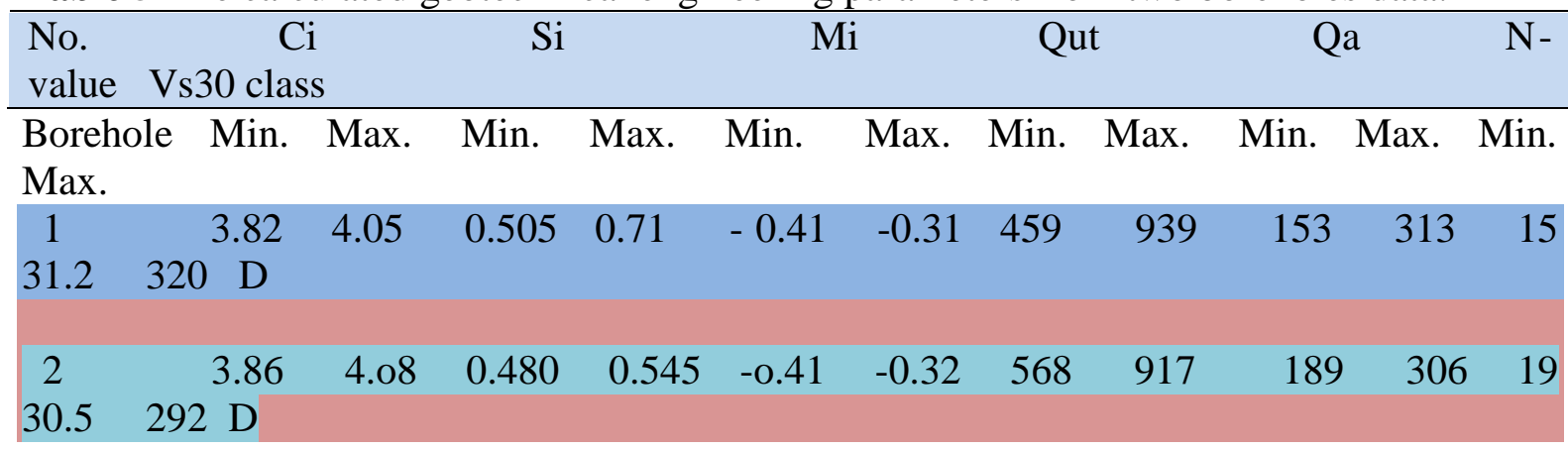

$\mathrm{Ci}=$ Concentration index, $\mathrm{Si}=$ Stress ratio, $\mathrm{Mi}=$ Material index, Qult $=$ ultimate bearing capacity $(\mathrm{Kg} / \mathrm{Cm} 2)$, and $\mathrm{Qa}=$ allowable bearing capacity $(\mathrm{Kg} / \mathrm{Cm} 2)$. 


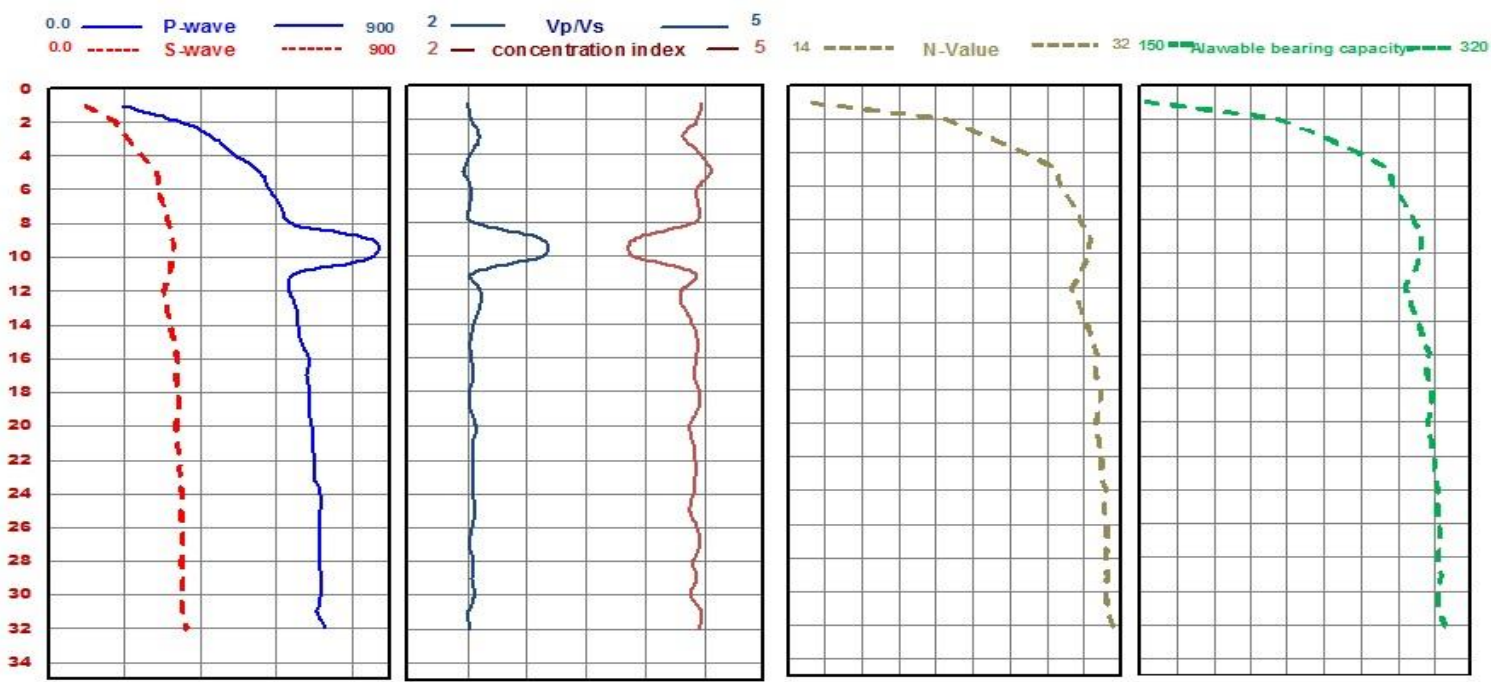

Figure 5- A graph of $\mathrm{P}$ and $\mathrm{S}$ waves, $\mathrm{Vp} / \mathrm{Vs}$, concentration index, $\mathrm{N}$ value, and allowable bearing capacity in borehole 1 .
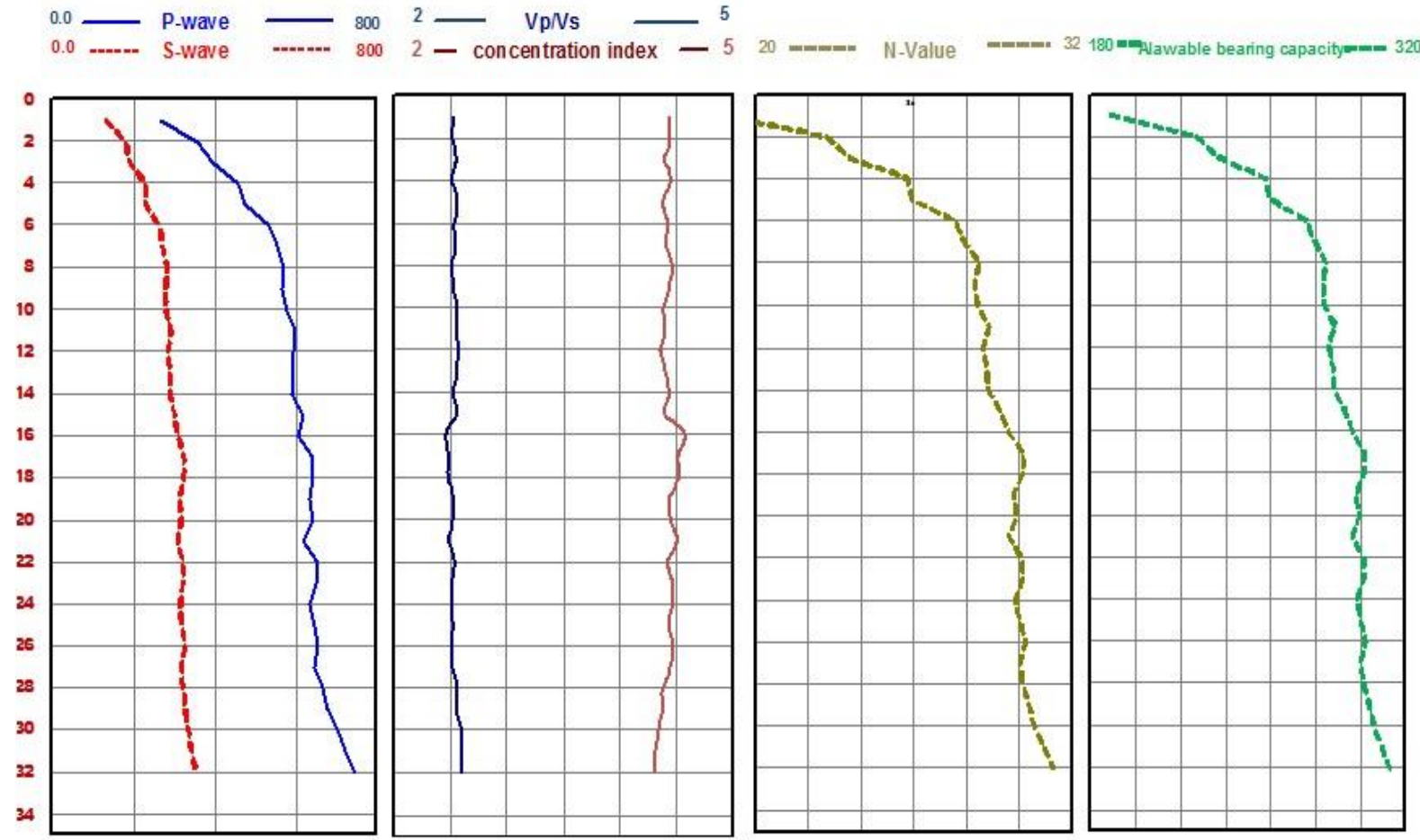

Figure 6 - Shows the graph between $\mathrm{P}$ and $\mathrm{S}$ waves, $\mathrm{Vp} / \mathrm{Vs}$ and conc. Index, $\mathrm{N}$ value and allowable bearing capacity in borehole 2 .

From the obtained results of the resistivity and seismic refraction surveys, a new empirical equation with a high correlation coefficient, $\mathrm{R}^{2}=0.9751$, was derived to predict the S-wave (97.5\%) for the bedrock in the study area (Figure 7), as follows:

$$
\mathrm{Vs}=1.0302 \rho+172.74
$$

where Vs is S-wave velocity and $\rho$ is the true resistivity.

This study aids in the estimation and prediction of the properties of the subsurface material (soils and rocks). It is especially useful in reducing the cost of drilling based on 
investigation as well as increasing the understanding of the Earth's subsurface geotechnical parameters.

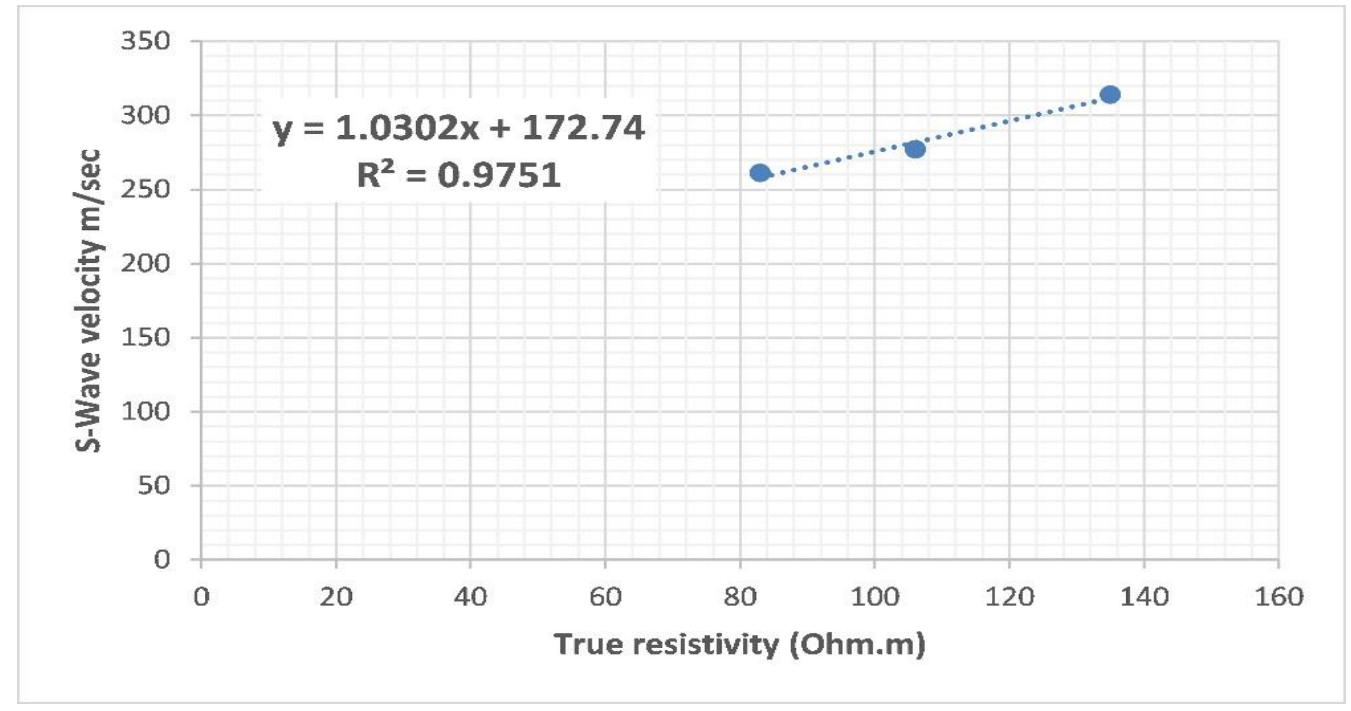

Figure 7- True Resistivity ( $\Omega . \mathrm{m})$ versus S-wave velocity $(\mathrm{m} / \mathrm{sec})$.

The correlation between resistivity, borehole, and down-hole data showed that the subsoil, i.e. less than $8 \mathrm{~m}$, has low and variable resistivity and shear wave values. This reflects that the subsurface soil is heterogeneous with low compaction and rigidity. Soil with lower shear wave velocity is lower in bearing capacity [10]. The values of resistivity and shear wave increased from the depth more than $6 \mathrm{~m}$ to the end of the borehole. This indicates that the competence and bearing capacity increase, as shown in Figures 5 and 6 . In addition, $\mathrm{N}$ values increased from top to bottom in the two boreholes. Finally, the NEHRP site classification revealed that soil classes in general reflect sites of class D.

\section{Conclusions}

ERT and shear wave data were used to delineate the subsurface soil's structural elements, and calculate the dynamic geotechnical properties of the soil in the Tenth of Ramadan City, which is a suggested site for the construction of factories. The results of the geotechnical properties of the soil and competence scales reveal that the competence of the soil increases with increasing the depth, ranging from fairly to moderately competent material. The integration between the results of ERT, seismic interpretation, and geotechnical properties of soil show that the study site consists of two subsurface layers; the uppermost is weathered soil, with a thickness of $6 \mathrm{~m}$, very low shear wave velocity, lower bearing capacity. The competence of the soil increase at depth more than $6 \mathrm{~m}$, characterized by not detectable subsurface structure (fracture or faults). Hence, it is concluded that this site is suitable for constructing factories. The present work can be utilized as a preliminary engineering site investigation technique to mitigate the potential hazards. It was intelligible that the information coming from ERT resistivity inversion and seismic refraction results allow describing the subsurface layers distribution with geoengineering data in a low cost strategy. Finally, the present study aids in the estimation and prediction of geotechnical properties of soils and rocks.

\section{References}

[1] Boudreault, J.P.; Dubé J.S.; Chouteau, M.; WiniarskiT. Hardy, É. "Geophysical characterization of contaminated urban fills". Engineering Geology, vol. 116, pp. 196-206, 2010 . 
[2] Araffa, S.A.S., Atya, M., Adel M.E. Mohamed, Mahmoud Gabala, Mohamed Abdel Zaher, Mamdouh, M. Soliman, Hany S. Mesbah, Usama Massoud, Hany M. Shaaban. "Subsurface investigation on Quarter 27 of May15th city, Cairo, Egypt using electrical resistivity tomography and shallow seismic Refraction Techniques". NRIAG Journal of Astronomy and Geophysics, 2014.

[3] Othman, A.A.A., "Construed geotechnical characteristics of foundation beds by seismic measurements". J. Geophys. Eng. Vol. 2, pp. 126-138, 2005.

[4] Khalil, M.H., Hanafy, S.M. 2008. "Engineering applications of seismic refraction method: A field example at Wadi Wardan, Northeast Gulf of Suez, Sinai, Egypt". Journal of Applied Geophysics, vol. 65, pp. 132- 141, 2008.

[5] Silva, C.P.L. Cartografia Geotécnica Tridimencional do Setor Noroeste de Brasília. Publicação G.TD 072/2011. Universidade de Brasília - UnB, Brasília, 299p. Tese (Doutorado), Departamento de Engenharia Civil Ambiental, 2011.

[6] Attwa M, El Shinawi A. Geoelectrical and geotechnical investigations at tenth of Ramadan City, Egypt - a structure based (SB) model application. Near surface geoscience 2014-20th European meeting of environmental and engineering geophysics, 2014.

[7] Eleraki, M., M. Gadallah, K. Gemail and M. Attwa, "Application of resistivity method in environmental study of the appearance of soil water in the central part of Tenth of Ramadan City, Egypt". Quarterly. Journal of Engineering Geology and Hydrology, vol. 43, pp. 171-184, 2010.

[8] Shebl S, Gemail KS, Attwa M, Soliman SA, Azab AA, Farag MH, "Utilizing shallow seismic refraction indefining the geotechnical properties of the foundation materials: a case study at New Minia City, Nile Valley", Egypt. J Pet. vol. 28, pp. 145-154, 2019.

[9] Gemail K.S., Shebl Salah, Attwa M., Soliman Shokry A., Azab Ahmed, Farag M.H. “ Geotechnical assessment of fractured limestone bedrock using DC resistivity method: a case study at New Minia City, Egypt", NRIAG Journal of Astronomy and Geophysics, vol. 9, no. 1, pp. 272- 279, 2020.

[10] Kramer, Steven L. Geotechnical Earthquake Engineering, Prentice Hall, 1996, p. 653.

[11] Said, R. The Geology of Egypt. Elsevier, Amsterdam, 1990.

[12] CONCO, Geological map of Egypt. Scale 1:500 000; Sheet Cairo. CONCO and the Egyptian General Petroleum Corporation, Cairo, 1987.

[13] El-Kadi, F. A, Drilling and Geotechnical investigation at the Tenth of Ramadan City, Cairo, Egypt. El Nile Engineering Consulting Office, Internal Report, 2019.

[14] Perrone A., Iannuzzi A. et al., "High-resolution electrical imaging of the Varco d'Izzo earthflow (southern Italy)". J Appl Geophys, vol. 56, no. 1, pp. 17-29, 2004.

[15] Loke, M.H, Tutorial: 2-D and 3-D electrical imaging surveys. Penang, Universiti Sains Malaysia, unpublished course notes. World Wide Web Address: www. Geoelectrical com., 2020.

[16] Geotomo . Manual RES2DINV Ver. 3.4. 2006. Penang, Malaysia, Geotomo Software, 132 p.

[17] Loke, M. H., and Barker, R. D., "Rapid least-squares inversion of apparent resistivity pseudosection by a quasi-Newton method". Geophys. Prospect., vol. 44, pp. 131-152, 1996.Sasaki, Y. "Resolution of resistivity tomography inferred from numerical simulation", Geophysical Prospecting, vol. 40, pp. 453-464, 1992.

[18] Gretener, P. 2003. Summary of the Poisson's Ratio debate 1990-2003. Feature Article, CSEG Recorder.28, 44-45.

[19] Salem, H. The theoretical and Practical Study of Petrophysical, Electric and Elastic Parameters of Sediments, Germany, Kiel Insitut for Geophysik. Ph.D.thesis, 1990.

[20] Telford, W.M., Sheriff, R.E., Applied geophysics, Cambridge university press, 1990.

[21] Toksöz, M.N., Cheng, C.H., Timur, A. "Velocities of seismic waves in porous rocks", Geophysics, vol. 41, pp. 621-645, 1976.

[22] Keceli, A. "Soil parameters which can be determined with seismic velocities", TMMOB Jeofizik Mühendisleri Odası, Jeofizik, vol. 16, pp. 17-29, 2012.

[23] Lowrie, W., Fundamentals of geophysics. Cambridge University Press, 2007.

[24] Mott, P., Dorgan, J., Roland, C., "The bulk modulus and Poisson's ratio of "incompressible" materials". Journal of Sound and Vibration, vol. 312, pp. 572-575, 2008. 
[25] Sivrikaya $O$ and Toğrol E., "Determination of undrained strength of fine-grained soils by means of SPT and its application in Turkey". Eng Geol. vol. 86, pp. 52-69, 2006.

[26] Anbazhagan P, Parihar A and Rashmi H N., "Review of correlations between SPT N and shear modulus: a new correlation applicable to any region Soil Dyn". Earthq. Eng., vol. 36, pp. 5269, 2012.

[27] Stuempel H, Kahler S, Meissner R and Milkereit B., "The use of seismic shear waves and compressional waves for lithological problems of shallow sediments Geophys". Prospect., vol. 32, pp. 662-75, 1984.

[28] Bowles, J. E. Physical and Geotechnical Properties of Soils, London: McGraw-Hill, 1984.

[29] Das, B. M. Principles of Geotechnical Engineering. PWS Publishing Company, 1994.

[30] Matasovic N, Kavazanjian E Jr., "Cyclic characterization of oil landfill solid waste". J Geotech Geoenviron Eng ASCE., vol. 124, no. 3, pp. 197-210, 1998.

[31] Sheriff, R.E. and Geldart, L.P., Exploration Seismology, Cambridge Univ. Press, Cambridge, 1986, p. 316.

[32] Parry, R.H.G. Estimating bearing capacity of sand from SPT values JGED ASCE 103: Gt.9, pp. 1014-1043, 1977.

[33] BSSC NEHRP, Recommended Provisions for seismic Regulations for New buildings and Other Structures, Part1: Provisions, FEMA 368, Federal Emergency Management Agency, Washington, D.C., 2003. 